\title{
The Prognostic Factors and Required Degree Influencing the Activities of Daily Living and Gait in Brain Impairment Patients with Hemiplegia
}

\author{
Seungsu Kim ${ }^{1,2}, * \mathbb{D}$, Jihye Park ${ }^{3}$ and Young Jin Ko ${ }^{4, *}$ \\ 1 Department of Rehabilitation Medicine, Graduate School of Medicine, The Catholic University of Korea, \\ Seoul 06591, Korea \\ 2 Department of Rehabilitation Medicine, Gyeonggi Provincial Medical Center Paju Hospital, Paju 10922, Korea \\ 3 Department of Rehabilitation Medicine, Eunpyeong St. Mary Hospital, College of Medicine, \\ The Catholic University of Korea, Seoul 03312, Korea; sophia@catholic.ac.kr \\ 4 Department of Rehabilitation Medicine, Seoul St. Mary Hospital, College of Medicine, \\ The Catholic University of Korea, Seoul 06591, Korea \\ * Correspondence: seungsukim@catholic.ac.kr (S.K.); yjko@catholic.ac.kr (Y.J.K.)
}

Citation: Kim, S.; Park, J.; Ko, Y.J.

The Prognostic Factors and Required

Degree Influencing the Activities of

Daily Living and Gait in Brain

Impairment Patients with

Hemiplegia. Disabilities 2021, 1 ,

187-201. https://doi.org/10.3390/

disabilities 1030015

Academic Editor: Donatella Petretto

Received: 22 May 2021

Accepted: 22 July 2021

Published: 27 July 2021

Publisher's Note: MDPI stays neutral with regard to jurisdictional claims in published maps and institutional affiliations.

Copyright: (c) 2021 by the authors. Licensee MDPI, Basel, Switzerland. This article is an open access article distributed under the terms and conditions of the Creative Commons Attribution (CC BY) license (https:// creativecommons.org/licenses/by/ $4.0 /)$.

\begin{abstract}
To improve the independence of brain impairment patients in ADL, we sought to identify influential parameters from information commonly collected in hospitals, prioritize the factors, and specify the degree to which those factors are necessary. In total, 64 patients with hemiplegia, who had been admitted to the one of the authors, were examined using various evaluation tools. Afterwards, we checked the difference between the capable group and the incapable group with an independent $t$-test or chi-squared test to determine the significant factors, and we prioritized the significant factors with Spearman's rho test. The degree of their necessity was determined with the ROC curve. Standing balancing ability and hip joint and knee extensor strength are necessary in most ADL except for eating. In order to independently perform most ADL except eating and one gait cycle, the strength of the knee extensor and hip flexor was required to exceed grade 3 on the MRC scale. However, one gait cycle was possible even if the strength of the hip joint and knee extensors rated lower than 3 on the MRC scale. Additionally, upper limb motor recovery was required up to the distal parts in the order of bathing, dressing, and grooming.
\end{abstract}

Keywords: gait; walking; hemiplegia; ADL (activities of daily living); stroke; TBI; rehabilitation; modified Barthel index

\section{Introduction}

Approximately 50 million stroke survivors worldwide have to deal with significant physical, cognitive, and emotional deficits, and $25-74 \%$ of stroke survivors are partially or fully dependent on caregivers for ADLs [1,2]. The proportion of stroke patients with hemiplegia is about $88 \%$ [3]. This study was conducted in patients with hemiplegia, who make up the majority of stroke patients. For hemiplegic patients, knowing what factors facilitate activities of daily living (ADL) and how much each factor is needed can help to improve independence in ADL.

There is much research on factors associated with ADL. Many studies have shown that motor recovery and balance are essential to the independent performance of ADL [4-14]. However, none of the studies listed above met all of the following three conditions: 1 . performing a comprehensive comparison of functional factors; 2 . using assessment tools readily available in all hospitals; 3 . providing information on the degree to which critical factors are needed. These studies used evaluation tools based on Brunnstrom stage, Fugl Meyer, walking speed, and dynamometers, which are not routinely used for stroke patients in most hospitals. Additionally, no specific study has been undertaken on the degree of motor recovery required to enable patients with hemiplegia to walk or 
perform ADL independently. For example, the following question has not been addressed: for a hemiplegic patient who has a hip flexor and extensor Medical Research Council (MRC) muscle grade of 2 (poor) and knee extensor, flexor and ankle dorsiflexor MRC grade of 1 (trace), and who cannot walk but can stand with a cane even after over 3 months of treatment, what does this patient lack, and need to improve, compared with other patients with hemiplegia who can walk? The assessment tools used to address this question may be tailored to, for example, the Medical Research Council's muscle scale, which is employed in most hospitals (Medical Research Council 1943: grade 0 (zero)—no contraction; 1 (trace) trace of contraction; 2 (poor) - active movement with gravity excluded; 3 (fair) - active movement against gravity; 4 (good) —active movement against gravity and resistance; 5 (normal) - normal strength) [15]. Dynamometers, which are used in many studies, are not available at all hospitals, and also do not reflect the difference in force magnitude for a motion according to each person's height and weight (for example, the absolute muscle strength required for a person $190 \mathrm{~cm}$ tall and weighing $100 \mathrm{~kg}$ to perform hip flexion against gravity does not equal the absolute muscle strength required for a person who is $160 \mathrm{~cm}$ tall and weighs $50 \mathrm{~kg}$ to perform the same action). Additionally, the problem with the scales used in pedestrian studies is the uncertainty surrounding how much walking must be undertaken. Another problem is the intra-individual variability in stride length, which makes the uniform determination of walking distance difficult. Considering these problems, this study established a reference distance to assess capacity for walking. One walking stride (both the left and right legs) was used as the reference so as to exclude the influence of the difference between individual lower-extremity lengths. Additionally, in order to establish an accurate treatment plan for the hemiplegic patient who is unable to walk given in the previous example, objective information on how much the patient lacks the factors necessary for walking compared to other ambulatory hemiplegic patients would be needed.

This study was designed to help patients with hemiplegia in rehabilitation planning by identifying the factors essential for independent ADL or walking, their prioritization, and the degree to which they are required, based on the easily measurable evaluation tools available in hospitals. In other words, through the above process, we tried to more objectively and accurately interpret the meaning of ADL-related data, which is widely and easily collected through rehabilitation medicine, according to statistical results. These interpretation results would be helpful for clinicians to make an accurate and efficient rehabilitation treatment plan.

\section{Materials and Methods}

\subsection{Participants}

The data of this study were collected directly by the first author. Among patients diagnosed with brain impairment by neurology or neurosurgery, all who had been admitted to the first author (from 1 September 2017 to 31 May 2018), agreed to participate in the study and did not have lesions or paralysis on both sides were included in the analysis.

However, data collection and examination were initiated at least 3 months after onset and at least 1 month after hospital admission. The consent form for this study was prepared in accordance with the criteria of the University IRB, and signed consent was obtained from the participants. For patients with cognitive impairment, written consent was obtained from both the patients and their guardians. Hemiplegic minors were not hospitalized during the period.

During the study period, 74 patients with hemiplegia were hospitalized under the care of the first author. In total, 8 of the patients were excluded from the study due missing consent from a legal guardian (2 patients), difficulty in contacting a guardian (1 patient), or patient refusal (5 patients), while 2 patients were excluded due to early discharge. Of the 64 enrolled patients, consisting of 42 male and 22 female, 35 had right hemiplegia, while 29 had left hemiplegia (Table 1). All patients with hemiplegia were included, and none were excluded except as described above. The following points should be taken into account 
when interpreting the results of this study. Although this study was conducted under the direction of the university, it was conducted on patients in a rehabilitation hospital where only rehabilitation physicians and orthopedic surgeons participated in treatment. According to the basic operating policy of this rehabilitation hospital, hospitalization of patients with severe internal disease or cerebral palsy is very rare. The research data were collected and labeled with an encrypted number, without the patients' names or resident registration numbers. Data were collected according to the standards of the Institutional Review Board of the university that approved the study (MC17OESI0063). Additionally, this study was registered to the clinical research information service (Registration number of Clinical Research Information Service (CRiS), Republic of Korea: KCT0004661).

Table 1. General characteristics of subjects.

\begin{tabular}{cc}
\hline Condition & Number \\
\hline Number of subjects & 64 \\
\hline Gender $(n)$ & Male 42, Female 22 \\
\hline Age (years) & $60.02 \pm 12.02 *$ \\
\hline Right hemiplegia $(n)$ & 35 \\
\hline Left hemiplegia $(n)$ & 29 \\
\hline Body mass index & $24.24 \pm 3.38^{*}$ \\
\hline Shoulder abduction limited range of motion & $20.31 \pm 41.36^{*}$ \\
\hline Shoulder external rotation limited range of motion & $11.48 \pm 24.16^{*}$ \\
\hline Ankle dorsiflexion limited range of motion & $19.97 \pm 16.83^{*}$ \\
\hline Cane or walker $(n)$ & 31 \\
\hline Paid caregiver $(n)$ & 28 \\
\hline
\end{tabular}

$n$ indicates number of subjects. ${ }^{*}$ Values are mean \pm standard deviation.

\subsection{Assessment}

All of the participants were assessed via the MRC muscle scale, modified functional balance grades (Table 2), limited range of motion, the modified Ashworth scale [16], and the finger-to-nose test, and we also considered the presence of paid caregivers, sensory loss, BMI (body mass index), K-MBI (Korean version of modified Barthel index: eating, personal hygiene, dressing, toileting, bathing) [17,18], 1 gait cycle, and the K-MMSE (Korean minimental state examination; the K-MMSE was used without our knowing that it was in an unauthorized form, but we have completed the necessary procedures for submission with the copyright holder (PARi)) [19]. No illiteracy was discovered during the K-MMSE evaluation. For patients with aphasia (who were difficult to test), dial plates were used.

Table 2. Functional balance grades in this study.

\begin{tabular}{cl}
\hline Grade & Description \\
\hline 4 (Normal) & $\begin{array}{l}\text { Maintaining balance without support and shifting weight in } \\
\text { all directions without interruption or deceleration }\end{array}$ \\
\hline 3 (Good) & $\begin{array}{l}\text { Maintaining balance without support, and maintaining balance } \\
\text { while picking object (in front of weaker foot) off floor (standing balance), } \\
\text { and shifting weight (sitting balance) }\end{array}$ \\
\hline 2 (Fair) & Maintaining balance without support \\
\hline 1 (Poor) & $\begin{array}{l}\text { Maintaining balance with handhold support without the } \\
\text { help of others or other equipment or objects (backrest, wall, etc.) }\end{array}$ \\
\hline 0 (Zero) & $\begin{array}{l}\text { Requiring help of others or other equipment of objects (backrest, wall, etc.). } \\
\text { No maintaining balance even with handhold support }\end{array}$ \\
\hline
\end{tabular}


The strength of the paralyzed limbs was evaluated according to the MRC muscle scale (Medical Research Council, 1943) [15].

LOM (limited range of motion) was determined by measuring the PROM (passive range of motion) with a goniometer and then subtracting this value from a normal ROM value.

Patient balance was assessed with a modified scale, after two other types of scales were considered $[20,21]$. The balance grades were expressed as normal, good, fair, poor or zero, presented in this paper as $4,3,2,1$, and 0 , respectively (Table 2).

The degree of sensory loss (10 g monofilament testing, light touch, position sense) was classified as normal (2), impaired (1) or lost (0). A 5.07 Semmes-Weinstein monofilament test and a light touch test were performed on the bottom of the 1st toe [22]. The light touch was provided by the author's fingertip [23]. The position sense of the patient was evaluated through the flexion and extension of the ankle joint with eyes closed. The reference point was an anti-symmetric position or face. If sensation was less than the face or the opposite position, a score of 1 was recorded.

Walking was determined to be possible when one gait cycle could be performed independently. In this study, one gait cycle involved both the left and the right leg and was visually confirmed. Starting with both feet on the same line, if the patient could perform a second initial contact on both sides, their ability to perform a gait cycle was confirmed. Walking $50 \mathrm{~m}$ was also evaluated. The $50 \mathrm{~m}$ walking test was conducted in the hospital hallway. The patient was required to walk along a line from a premarked starting point that they reached via wheelchair. The degree of independence in performing basic ADL was evaluated using the K-MBI $[17,18]$.

Elbow-, knee-, and ankle-joint spasticity were assessed using the modified Ashworth scale. The presence of dysmetria was assessed using the finger-to-nose test. The role of a paid caregiver was assessed in terms of whether they had a negative impact on a patient's ability to perform ADL independently.

\subsubsection{Walking}

Walking was evaluated by the performance of 1 gait cycle and walking $50 \mathrm{~m}$. One gait cycle was set as the threshold since this is the smallest unit of walking. We assumed that if achieving one gait cycle or walking $50 \mathrm{~m}$ was possible without the help of others, it would also be possible with the use of canes, walkers, or railings (which are most beneficial to subjects). Additionally, assistance was offered by reaching aids, and the test was performed on level ground.

\subsubsection{Feeding}

Eating was divided into capable and incapable groups based on the criteria of MBI level III. Patients in the capable group are able to feed themselves with supervision; these patients required assistance with associated tasks, such as putting milk/sugar into their tea, adding salt to food, turning a plate, or other "set up" activities.

\subsubsection{Personal Hygiene (Grooming)}

Grooming was divided into capable and incapable groups based on the criteria of MBI level IV. Patients in the capable group were able to groom themselves but required minimal assistance before and/or after the operation.

\subsubsection{Dressing}

Dressing was divided into capable and incapable groups based on the criteria of MBI level IV. Patients in the capable group could fasten clothes with buttons, zips, shoes, etc., with only minimal assistance. 


\subsubsection{Toileting}

Toileting was divided into capable and incapable groups based on the criteria of MBI level IV. Patients in the capable group may require supervision with normal toileting for the sake of safety. For these patients, a commode can be used at night, but assistance is required for emptying and cleaning.

\subsubsection{Bathing}

Bathing was divided into capable and incapable groups based on the criteria of MBI level IV. For the capable group, supervision is required for the sake of safety in adjusting the water temperature, or in the transfer into/out of the bath.

\subsection{Statistics}

The participants were divided into capable and incapable groups, and analyzed using the chi-squared test and independent $t$-test, Spearman's rho test, and ROC curves.

The significant factors identified using the chi-squared test or the independent $t$ test were subsequently reanalyzed via Spearman's rho test and ROC curve. Through Spearman's Rho test, the order of importance among the significant factors was determined. Additionally, the highest point of sensitivity and specificity was determined via the ROC curve [24]. Statistical analyses were performed using IBM SPSS version 25 (IBM, New York, NY, USA). Since this study was explorative, we used the final results to perform sample tests with $80 \%$ power and alpha 0.05 , and the numbers of participants required in the control and experimental groups for the statistical processing of each ADL and gait were less than the numbers actually used in this study.

\section{Results}

Table 3 shows the results of the chi-squared and independent $t$-test for each ADL. Any factors that were found to be different via the chi-square test or independent $t$-test were analyzed with Spearman's rho test, and factors with a Spearman's correlation coefficient of 0.6 or more were adopted (Table 4) [25]. One reason for this was that this study sought to prioritize the significant factors. Another reason was that, in the stroke recovery process, when the upper extremities recover, the lower extremities tend to improve as well. In other words, even if hand strength is statistically related to independent walking, it can be regarded as a result of the relationship between the strength of the hand and the strength of the hip or knee joint. Therefore, even if the MRC muscle scale results for the joints show significant correlations with independent walking, they may not actually be related unless their values are significantly high. The ROC curve was used on these variables to find the cut-off values with the greatest sensitivity and specificity.

Table 3. Chi-squared test or independent $t$-test results ${ }^{\dagger}$.

\begin{tabular}{|c|c|}
\hline ADL & The significant factors calculated from chi-squared test or independent $t$-test \\
\hline $\begin{array}{c}\text { Gait } \\
(p<0.05)\end{array}$ & $\begin{array}{l}\text { Chi-squared test: Hip flexor/extensor/abductor/adductor, Knee flexor/extensor, } \\
\text { Ankle dosriflexor/plantarflexor, Shoulder flexor/extensor/abductor/adductor, Elbow flexor/extensor, } \\
\text { Wrist flexor/extensor, Hand flexor, Thumb flexor, Index flexor, Balance (sitting, standing), Position sense } \\
\text { Independent } t \text {-test: Body mass index }\end{array}$ \\
\hline $\begin{array}{c}50 \mathrm{~m} \\
\text { Walking }\end{array}$ & $\begin{array}{l}\text { Chi-squared test: Hip flexor/extensor/abductor/adductor, Knee flexor/extensor, Ankle } \\
\text { dosriflexor/plantarflexor, Shoulder flexor/extensor/abductor/adductor, Elbow flexor/extensor, Wrist } \\
\text { flexor/extensor, Thumb flexor/extensor, Index flexor/extensor, Hand flexor/extensor, Balance (sitting, standing) } \\
\text { Independent } t \text {-test: K-MMSE, Age (negative direction), Body mass index, Shoulder abduction LOM } \\
\text { (negative direction) }\end{array}$ \\
\hline Feeding & $\begin{array}{l}\text { Chi-squared test: Hip flexor/extensor/abductor/adductor, Knee flexor/extensor, Ankle plantarflexor, } \\
\text { Shoulder extensor/abductor/adductor, Elbow flexor, Balance (sitting, standing), Position sense } \\
\text { Independent } t \text {-test: Body mass index }\end{array}$ \\
\hline
\end{tabular}


Table 3. Cont.

\begin{tabular}{|c|c|c|c|c|}
\hline Grooming & \multicolumn{4}{|c|}{$\begin{array}{l}\text { Chi-squared test: Hip flexor/extensor/abductor/adductor, Knee flexor/extensor, Ankle } \\
\text { dorsiflexor/plantarflexor, Shoulder flexor/extensor/abductor/adductor, Elbow flexor/extensor, Wrist } \\
\text { flexor/extensor, Hand flexor/extensor, Thumb flexor/extensor, Index flexor/extensor, Balance (sitting, standing) } \\
\text { Independent } t \text {-test: Body mass index, Limited range of motion (negative direction: shoulder } \\
\text { abduction/external rotation) }\end{array}$} \\
\hline Dressing & \multicolumn{4}{|c|}{$\begin{array}{l}\text { Chi-squared test: Hip flexor/extensor/abductor/adductor, Knee flexor/extensor, Ankle } \\
\text { dorsiflexor/plantarflexor, Shoulder flexor/extensor/abductor/adductor, Elbow flexor/extensor, } \\
\text { Wrist flexor/extensor, Thumb flexor/extensor, Index flexor/extensor, Hand flexor/extensor, } \\
\text { Balance (Sitting and standing), Paid caregiver } \\
\text { Independent } t \text {-test: Age (negative direction), Body mass index, Limited range of } \\
\text { motion (negative direction: shoulder external rotation, shoulder abduction) }\end{array}$} \\
\hline Toileting & \multicolumn{4}{|c|}{$\begin{array}{l}\text { Chi-squared test: Hip flexor/extensor/abductor/adductor, Knee flexor/extensor Ankle } \\
\text { dorsiflexor/plantarflexor, Shoulder flexor/extensor/abductor/adductor, Elbow flexor/extensor, } \\
\text { Wrist flexor/extensor, Thumb flexor/extensor, Hand flexor/extensor, Index flexor/extensor, } \\
\text { Balance (sitting and standing) } \\
\text { Independent } t \text {-test: Age (negative direction), Body mass index, Limited range of motion } \\
\text { (negative direction: shoulder external rotation, abduction) }\end{array}$} \\
\hline Bathing & \multicolumn{4}{|c|}{$\begin{array}{l}\text { Chi-squared test: Hip flexor/extensor/abductor/adductor, Knee flexor/extensor, Ankle } \\
\text { dorsiflexor/plantarflexor, Shoulder flexor/extensor/abductor/adductor, Elbow flexor/extensor, } \\
\text { Wrist flexor/extensor, Thumb flexor/extensor, Index flexor/extensor, Hand flexor/extensor, } \\
\text { Balance (sitting and standing), Cane, Paid caregiver, Modified Ashworth scale (ankle) } \\
\text { Independent } t \text {-test: Age (negative direction), Body mass index, Limited range of } \\
\text { motion (negative direction: shoulder abduction/external rotation) }\end{array}$} \\
\hline \multicolumn{5}{|c|}{$\begin{array}{l}\text { This table shows the significant factors from chi-squared test or independent } t \text {-test }(p<0.05) \text {. Insignificant factors were excluded for brevity. } \\
+ \text { For the same purpose, the MRC muscle score of hip flexor, etc., was briefly expressed as "hip flexor", etc. Additional data is in the } \\
\text { Supplementary (Tables S4, S8, S12, S16, S20, S24 and S28). }\end{array}$} \\
\hline \multicolumn{5}{|c|}{ Table 4. Spearman's rho test ${ }^{\dagger}$. } \\
\hline \multicolumn{5}{|l|}{ Gait } \\
\hline Sitting balance & Standing balance & Hip flexor & Hip extensor & Hip abductor \\
\hline $0.798^{* *}$ & $0.738^{* *}$ & $0.653^{* *}$ & $0.656^{* *}$ & 0.641 ** \\
\hline Hip adductor & Knee extensor & & & \\
\hline $0.650^{* *}$ & $0.648^{* *}$ & & & \\
\hline \multicolumn{5}{|l|}{ Feeding } \\
\hline \multicolumn{5}{|l|}{ Sitting Balance } \\
\hline \multicolumn{5}{|l|}{$0.745^{* *}$} \\
\hline \multicolumn{5}{|l|}{ Grooming } \\
\hline Standing balance & Sitting balance & Hip extensor & Hip abductor & Hip adductor \\
\hline $0.653^{* *}$ & $0.616^{* *}$ & $0.625^{* *}$ & $0.644^{* *}$ & $0.649 * *$ \\
\hline Hip flexor & Shoulder adductor & Knee extensor & & \\
\hline $0.647^{* *}$ & $0.622 * *$ & $0.655^{* *}$ & & \\
\hline \multicolumn{5}{|l|}{ Dressing } \\
\hline Knee extensor & Standing balance & Hip abductor & Hip adductor & Shoulder extensor \\
\hline $0.703^{* *}$ & $0.670 * *$ & $0.671^{* *}$ & $0.669 * *$ & $0.636^{* *}$ \\
\hline Hip Flexor & Shoulder adductor & Shoulder abductor & Elbow flexor & Elbow extensor \\
\hline $0.661^{* *}$ & $0.653^{* *}$ & $0.633 * *$ & $0.653 * *$ & $0.654^{* *}$ \\
\hline \multicolumn{5}{|l|}{ Hip extensor } \\
\hline $0.669^{* *}$ & & & & \\
\hline
\end{tabular}


Table 4. Cont.

\begin{tabular}{|c|c|c|c|c|}
\hline Toileting & & & & \\
\hline Standing balance & Hip abductor & Hip adductor & Knee extensor & Hip flexor \\
\hline $0.648^{* *}$ & $0.607^{* *}$ & $0.610 * *$ & $0.634^{* *}$ & $0.608^{* *}$ \\
\hline \multicolumn{5}{|l|}{ Hip extensor } \\
\hline \multicolumn{5}{|l|}{$0.598^{* *}$} \\
\hline \multicolumn{5}{|l|}{ Bathing } \\
\hline Elbow flexor & Shoulder flexor & Shoulder extensor & Shoulder abductor & Shoulder adductor \\
\hline $0.689^{* *}$ & $0.644^{* *}$ & $0.644^{* *}$ & $0.607^{* *}$ & $0.685^{* *}$ \\
\hline Knee flexor & Elbow extensor & Hand flexor & Wrist extensor & Wrist flexor \\
\hline $0.601 * *$ & $0.654^{* *}$ & $0.638^{* *}$ & $0.657^{* *}$ & $0651^{* *}$ \\
\hline Thumb flexor & Knee extensor & Standing balance & & \\
\hline $0.638^{* *}$ & $0.584 * *$ & $0.570 * *$ & & \\
\hline \multicolumn{5}{|l|}{$50 \mathrm{~m}$ walking } \\
\hline Standing balance & Hip flexor & Hip extensor & Hip abductor & Hip adductor \\
\hline $0.747^{* *}$ & $0.678^{* *}$ & $0.665^{* *}$ & $0.638^{* *}$ & $0.641^{* *}$ \\
\hline Knee extensor & Knee flexor & Shoulder flexor & Shoulder extensor & Shoulder abductor \\
\hline $0.686^{* *}$ & $0.646^{* *}$ & $0.600 * *$ & $0.621^{* *}$ & $0.611^{* *}$ \\
\hline Shoulder adductor & Elbow flexor & Sitting balance & & \\
\hline $0.660 * *$ & $0.605^{* *}$ & $0.673 * *$ & & \\
\hline
\end{tabular}

${ }^{* *} p<0.01$. This table shows the significant results (Spearman's rho $>0.6$ ) from Spearman's rho test. Insignificant or some significant but relatively lower correlation were excluded for brevity. ${ }^{\dagger}$ For the same purpose, the MRC muscle score of hip flexor, etc., was briefly expressed as "hip flexor", etc. Additional data is in the Supplementary (Tables S1, S2, S5, S6, S9, S10, S13, S14, S17, S18, S21, S22, S25 and S26).

\subsection{Chi-Squared or Independent $T$ Test for $A D L$}

For the chi-square and independent tests, the factors that showed differences between the capable and incapable groups in terms of one gait cycle, $50 \mathrm{~m}$ walking, eating, grooming, dressing, toileting, and bathing are summarized in Table 3 (Insignificant factors were excluded for brevity. All relevant data are in the Supplementary Materials (Tables S1, S2, S5, S6, S9, S10, S13, S14, S17, S18, S21, S22, S25 and S26)).

\subsection{Spearman's Rho Test of Each ADL}

Table 4 shows the significant results from the Spearman's rho test. The factors with a correlation coefficient $\geq 0.6$ [25] were balancing ability, hip joint strength, and knee extensor in one gait cycle; balancing ability, hip and shoulder joint strength, and knee extensor and elbow flexor in $50 \mathrm{~m}$ walking; sitting balance in feeding; balancing ability, hip joint strength, knee extensor, and shoulder adductor in grooming; hip and elbow joint strength, knee extensor, and shoulder extensor/abductor/adductor in dressing; standing balance, hip flexor/abductor/adductor and knee extensor in toileting; shoulder, elbow, and wrist joint strength, hand flexor, and knee flexor in bathing.

Taken together the above results, upper limb motor recovery was required for bathing, dressing, and grooming. In order to bathe, muscle strength was required up to the hand, while dressing required muscle strength recovery to the elbow joint and grooming required it to the shoulder (as shown in Table 4, strength-related factors with correlation coefficient $\geq 0.6$ in upper extremity: shoulder adductor in grooming; elbow joint strength, and shoulder extensor/abductor/adductor in dressing; shoulder/elbow/wrist joint strength, and hand flexor in bathing). In grooming, shoulder adductor strength was more required than strength in the other shoulder joint muscles, since only the muscle strength of the shoulder adductor in the upper extremity has a correlation coefficient $\geq 0.6$ (Table 4). 
The following summarizes the results for the factors that are not related to muscle strength even though their Spearman's rho values were below 0.6: K-MMSE showed a positive correlation with most ADL except for one gait cycle (Spearman's rho test results: eating $0.455^{* *}$, grooming $0.459^{* *}$, dressing $0.450^{* *}$, toileting $0.426^{* *}$, bathing $0.320^{* *}, 50 \mathrm{~m}$ walking $0.431^{* *},{ }^{* *} p<0.01$; see Supplementary Materials (Tables S3, S7, S11, S15, S19 and S27)), and BMI was positively correlated with all ADL (Spearman's rho test results: $0.287 \sim 0.363 *{ }^{*} p<0.05$; see Supplementary Materials (Tables S3, S7, S11, S15, S19, S23 and S27)). Compared to other ADL, limitations to the shoulder joint's range of motion in dressing showed a higher correlation (Spearman's rho test results: shoulder abduction LOM, $-0.531^{* *}$; shoulder external rotation LOM, $-0.350^{* * ;}{ }^{* *} p<0.01$; see Supplementary Materials (Table S11)).

\subsection{ROC Curve of Each ADL}

The receiver operating characteristic (ROC) curve was applied to the variables with a Spearman's correlation coefficient $\geq 0.6$ in order to determine the cut-off values with the greatest sensitivity and specificity. These values were determined according to the maximum Youden's index and the minimum distance from the upper-left corner of the unit square (Table 5, Figure 1) [26]. When the maximum Youden's index and the minimum distance from the upper-left corner of the unit square were different, the cut-off value with the higher sensitivity was selected. As regards specificity, the cut-off value for a certain factor can be increased, which can lead to a false-negative prediction of ability. The cut-off points of the main significant factors mentioned earlier were as follows (Table 5) (the MRC muscle scale (zero $=0$, trace $=1$, poor $=2$, fair $=3$, good $=4$, normal $=5$ ) was used and analyzed statistically): hip extensor, 2.5; other hip joint strength, knee extensor and standing balance, 1.5 in one gait cycle (that is, standing balance for gait was >poor, as assessed using the results obtained by applying the balance grades in Table 2 (modified functional balance grade (zero $=0$, poor $=1$, fair $=2$, good $=3$, normal $=4$ ) was used and analyzed statistically); hip flexor/extensor/adductor, 3.5; hip abductor, 2.5; knee extensor, 3.5; standing balance, 2; shoulder extensor/adductor, 2.5; shoulder flexor/abductor, 1.5; elbow flexor, 1.5 in the $50 \mathrm{~m}$ walking test. Compared to the one gait cycle test, the demand for muscle strength and balancing ability was increased in the $50 \mathrm{~m}$ walking test, and muscle strength in the upper limbs was also required.

Table 5. ROC-curve results ${ }^{\dagger}$.

\begin{tabular}{|c|c|c|c|c|c|}
\hline & Sensitivity & Specificity & Cut-Off Value & Area Under ROC & $p$ \\
\hline \multicolumn{6}{|l|}{ Gait } \\
\hline Standing balance & 0.962 & 0.909 & 1.50 & 0.983 & 0.000 \\
\hline Sitting balance & 0.962 & 0.818 & 2.5 & 0.901 & 0.000 \\
\hline Hip flexor & $\begin{array}{c}1 \\
0.887\end{array}$ & $\begin{array}{l}0.818 \\
0.909\end{array}$ & $\begin{array}{l}1.5 \text { (by Maximum Youden's index) } \\
2.5 \text { (by Maximum Youden's index) }\end{array}$ & 0.951 & 0.000 \\
\hline Hip extensor & 0.906 & 0.909 & 2.5 & 0.945 & 0.000 \\
\hline Hip abductor & $\begin{array}{l}0.962 \\
0.868\end{array}$ & $\begin{array}{l}0.818 \\
0.909\end{array}$ & $\begin{array}{l}1.5 \text { (by Maximum Youden's index) } \\
2.5 \text { (by minimum distance from } \\
\text { left-upper corner of unit square) }\end{array}$ & 0.943 & 0.000 \\
\hline Hip adductor & 0.962 & 0.909 & 1.5 & 0.949 & 0.000 \\
\hline Knee extensor & 0.981 & 0.909 & 1.5 & 0.944 & 0.000 \\
\hline \multicolumn{6}{|l|}{ Feeding } \\
\hline Sitting balance & 0.962 & 0.818 & 2.5 & 0.901 & 0.000 \\
\hline
\end{tabular}


Table 5. Cont.

\begin{tabular}{|c|c|c|c|c|c|}
\hline & Sensitivity & Specificity & Cut-Off Value & Area Under ROC & $p$ \\
\hline \multicolumn{6}{|l|}{ Grooming } \\
\hline Sitting balance & 0.978 & 0.526 & 2.5 & 0.756 & 0.001 \\
\hline Standing balance & 0.822 & 0.789 & 2.5 & 0.853 & 0.000 \\
\hline Hip flexor & 0.911 & 0.737 & 3.5 & 0.87 & 0.000 \\
\hline Hip extensor & 0.933 & 0.684 & 3.5 & 0.85 & 0.000 \\
\hline Hip abductor & 0.933 & 0.737 & 2.5 & 0.868 & 0.000 \\
\hline Hip adductor & 0.911 & 0.737 & 3.5 & 0.871 & 0.000 \\
\hline Knee extensor & 0.911 & 0.737 & 3.5 & 0.871 & 0.000 \\
\hline Shoulder adductor & 0.733 & 0.895 & 2.5 & 0.884 & 0.000 \\
\hline \multicolumn{6}{|l|}{ Dressing } \\
\hline Knee extensor & 1 & 0.643 & 3.5 & 0.866 & 0.000 \\
\hline Standing balance & 0.917 & 0.714 & 2.5 & 0.833 & 0.000 \\
\hline Hip adductor & 0.972 & 0.607 & 3.5 & 0.852 & 0.000 \\
\hline Hip abductor & 1 & 0.607 & 2.5 & 0.853 & 0.000 \\
\hline Hip flexor & 0.972 & 0.607 & 3.5 & 0.848 & 0.000 \\
\hline Hip extensor & 1 & 0.571 & 3.5 & 0.845 & 0.000 \\
\hline Shoulder abductor & 0.944 & 0.643 & 1.5 & 0.860 & 0.000 \\
\hline Shoulder adductor & 0.722 & 0.893 & 3.5 & 0.871 & 0.000 \\
\hline Shoulder extensor & 0.861 & 0.786 & 2.5 & 0.861 & 0.000 \\
\hline Elbow flexor & 0.917 & 0.679 & 1.5 & 0.870 & 0.000 \\
\hline Elbow extensor & 0.944 & 0.607 & 0.5 & 0.869 & 0.000 \\
\hline \multicolumn{6}{|l|}{ Toileting } \\
\hline Standing balance & 0.857 & 0.773 & 2.5 & 0.837 & 0.000 \\
\hline Hip flexor & 0.905 & 0.636 & 3.5 & 0.834 & 0.000 \\
\hline Hip abductor & 0.929 & 0.636 & 2.5 & 0.833 & 0.000 \\
\hline Hip adductor & 0.952 & 0.591 & 2.5 & 0.835 & 0.000 \\
\hline Hip extensor & 0.952 & 0.591 & 2.5 & 0.822 & 0.000 \\
\hline Knee extensor & 0.929 & 0.682 & 3.5 & 0.845 & 0.000 \\
\hline \multicolumn{6}{|l|}{ Bathing } \\
\hline Knee flexor & 0.889 & 0.622 & 2.5 & 0.840 & 0.000 \\
\hline Hip extensor & 1 & 0.432 & 3.5 & 0.797 & 0.000 \\
\hline Hip adductor & 0.963 & 0.459 & 3.5 & 0.796 & 0.000 \\
\hline Hip flexor & 0.963 & 0.459 & 3.5 & 0.792 & 0.000 \\
\hline Shoulder adductor & 0.926 & 0.73 & 2.5 & 0.89 & 0.000 \\
\hline Shoulder extensor & 0.963 & 0.703 & 2.5 & 0.867 & 0.000 \\
\hline Elbow flexor & 0.815 & 0.838 & 3.5 & 0.892 & 0.000 \\
\hline Shoulder flexor & 0.815 & 0.757 & 2.5 & 0.868 & 0.000 \\
\hline Shoulder abductor & 1 & 0.541 & 1.5 & 0.847 & 0.000 \\
\hline Elbow extensor & 0.889 & 0.703 & 2.5 & 0.87 & 0.000 \\
\hline Wrist flexor & 0.630 & 0.919 & 3.5 & 0.865 & 0.000 \\
\hline
\end{tabular}


Table 5. Cont

\begin{tabular}{|c|c|c|c|c|c|}
\hline & Sensitivity & Specificity & Cut-Off Value & Area Under ROC & $p$ \\
\hline Wrist extensor & 0.630 & 0.919 & 3.5 & 0.868 & 0.000 \\
\hline Hand flexor & 0.926 & 0.676 & 0.5 & 0.855 & 0.000 \\
\hline Standing balance & 0.963 & 0.595 & 2.5 & 0.785 & 0.000 \\
\hline Knee extensor & 1 & 0.486 & 3.5 & 0.806 & 0.000 \\
\hline \multicolumn{6}{|l|}{$50 \mathrm{~m}$ Walking } \\
\hline Standing balance & 0.864 & 0.85 & 2.5 & 0.898 & 0.000 \\
\hline Hip flexor & 0.932 & 0.75 & 3.5 & 0.881 & 0.000 \\
\hline Hip extensor & 0.955 & 0.7 & 3.5 & 0.867 & 0.000 \\
\hline Hip abductor & 0.932 & 0.7 & 2.5 & 0.859 & 0.000 \\
\hline Hip adductor & 0.909 & 0.7 & 3.5 & 0.861 & 0.000 \\
\hline Knee extensor & 0.932 & 0.75 & 3.5 & 0.882 & 0.000 \\
\hline Knee flexor & 0.864 & 0.8 & 1.5 & 0.89 & 0.000 \\
\hline Shoulder flexor & 0.795 & 0.8 & 1.5 & 0.865 & 0.000 \\
\hline Shoulder extensor & 0.773 & 0.85 & 2.5 & 0.877 & 0.000 \\
\hline Shoulder abductor & 0.886 & 0.75 & 1.5 & 0.872 & 0.000 \\
\hline Shoulder adductor & 0.75 & 0.9 & 2.5 & 0.901 & 0.000 \\
\hline Elbow flexor & 0.864 & 0.8 & 1.5 & 0.867 & 0.000 \\
\hline
\end{tabular}

Note that MRC muscle scale 1 is grade trace and will be displayed as 1.0 in the Cut-Off Value. Standing balance 1 corresponds to grade poor.

${ }^{\dagger}$ For brevity, the MRC muscle score of hip flexor, etc., was briefly expressed as "hip flexor", etc. Additional data is in the Supplementary (Tables S4, S8, S12, S16, S20, S24 and S28).

The other results in Table 5 are as follows. In feeding, the requirement of the function of the paralyzed side was minimum compared to in other basic ADL, except for sitting balance. Overall, except for eating and one gait cycle, the flexor (other hip joint strength > poor or fair) and knee extensor strength had to grade above fair in the MRC muscle scale, as did standing balance. For grooming, dressing, toileting, bathing, and $50 \mathrm{~m}$ walking, a standing balance of 2.5 steps and a hip flexor and knee extensor MRC grade of 3.5 or more were required.

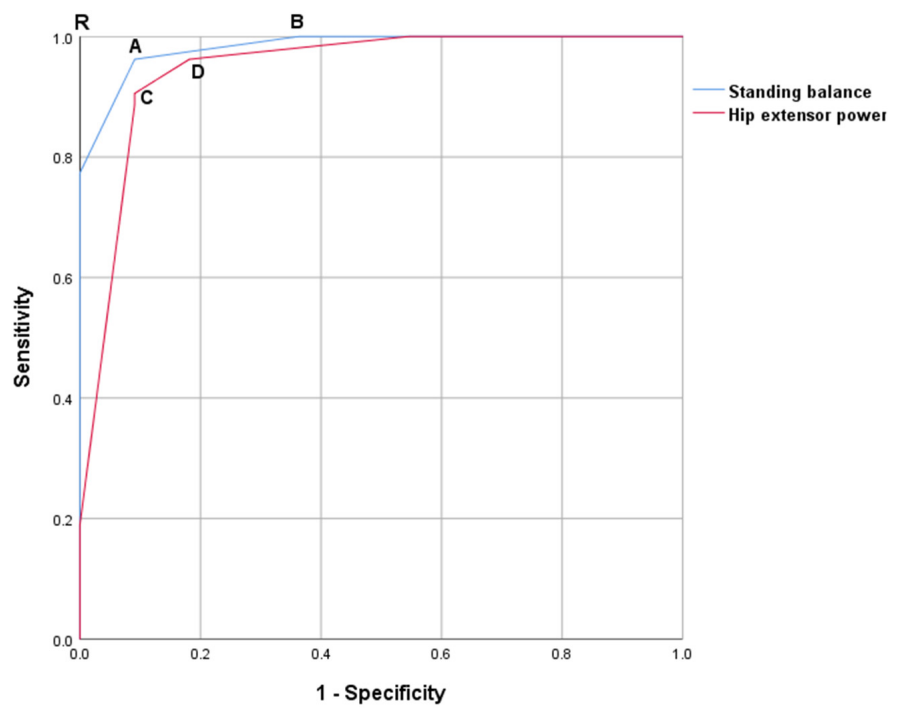

Figure 1. ROC curves of standing balance and hip extensor power for gait (1 gait cycle). 
The cut-off point of standing balance and hip extensor power are point $\mathrm{A}$ and point $C$, respectively. Point A or $C$ is closer to point $R$ (sensitivity 1 , specificity 1 ) than point $B$ or D. Additionally, the sum of the sensitivity and specificity of point $A$ or $C$ is larger than that of point B or D (coordinate values are given in the SPSS statistics program: point A: sensitivity 0.962 , specificity $0.909(1-0.091)$, sum 1.871 ; point B: sensitivity 1 , specificity 0.636 (1-0.364), sum $1.636, / /$ point $C$ : sensitivity 0.906 , specificity $0.909(1-0.091)$, sum 1.815 ; point $\mathrm{D}$ : sensitivity 0.962 , specificity $0.818(1-0.182)$, sum 1.780$)$. Therefore, point $\mathrm{A}$ is the cut-off point of the standing balance for 1 gait cycle. Additionally, point $C$ is the cut-off point of the hip extensor for 1 gait cycle. The value at point A is 1.5 (coordinate values are given in the SPSS statistics program), which corresponds to a value between standing balance poor and fair (the values for standing balance zero $=0$, poor $=1$, fair $=2$, good $=3$, normal $=4$ were set and analyzed statistically). The value at point $C$ is 2.5 (coordinate values are given in the SPSS statistics program), which corresponds to a value between hip extensor MRC scores of 2 and 3.

\section{Discussion}

According to Duncan et al. (2000) and Brandstater et al. (2010), complete functional recovery, when it occurs, is usually achieved within 3 months of onset $[27,28]$. As such, data collected before 3 months might not represent the individual functional maximum that can be derived from the strength being evaluated. Therefore, the data were collected 3 months after the onset of stroke, when the patient's functionality had potentially reached its maximum. Of course, this evaluation would have been more accurate if it had been performed more than 6 months after the onset. However, if the data were collected after 6 months, the data collection would have been more difficult and taken longer due to the increased rate of discharge of recovered patients. The data were collected at least one month after admission for the accuracy of assessment.

\subsection{Walking}

Walking was evaluated with one gait cycle and $50 \mathrm{~m}$ of walking. According to the combined results of the chi-squared test, the independent $t$-test, Spearman's rho test, and the ROC curves, when the hip extensor MRC muscle and standing balance grades are above poor, and there is only minimal muscle strength (>MRC muscle grade of trace (1)) in the other hip muscles and the knee extensor, the achievement of one gait cycle in a patient with hemiplegia can be predicted 3 months after onset (as shown in Table 5, the cut-off points of one gait cycle: hip extensor, 2.5; other hip joint strength, knee extensor and standing balance, 1.5. When interpreting these results, it should be taken into account that MRC muscle scale 1 is grade trace and will be displayed as 1.0 in the cut-off value. Standing balance 1 corresponds to grade poor).

In the $50 \mathrm{~m}$ walking assessment, higher levels of muscle strength and balance were required compared to the one gait cycle test. For $50 \mathrm{~m}$ walking, the grade of the hip flexor/extensor/adductor and knee extensor muscle strength, as well as the standing balance ability, were better than fair in the MRC muscle scale or modified functional balance grades. As shown in Table 5, the cut-off points of $50 \mathrm{~m}$ walking: hip flexor/extensor/ adductor, 3.5; hip abductor, 2.5; knee extensor, 3.5; standing balance, 2; shoulder extensor/adductor, 2.5; shoulder flexor/abductor, 1.5; elbow flexor, 1.5. Additionally, not only the lower extremity, but also the upper extremity recovery, were related. Many papers have suggested the role of the shoulder adductor in walking [29-32]. This may be because holding an arm against the body can help with walking, as suggested by the relationship between armsling use and walking in the already published papers, or because the arms also recover when the lower extremities recover, rather than there being a direct relation to walking. 


\subsection{Feeding}

In Table 4, we see that the factor with a correlation coefficient $\geq 0.6$ is sitting balance. The cut-off point of this factor was 2.5 (Table 5). Eating may require a balancing ability (sitting balance $>$ fair).

\subsection{Personal Hygiene (Grooming)}

Tables 4 and 5 show that grooming requires a greater balancing ability and hip and knee joint strength than eating. This is probably attributable to patients having to stand to use a sink. In addition, the shoulder adductor muscle requires more strength than the other shoulder joint muscles. In grooming, only the muscle strength of the shoulder adductor in the upper extremity has a correlation coefficient $\geq 0.6$ (Table 4 ). If the shoulder adductor muscle is used while the patient washes their hands, a healthy upper limb can help in this activity, since the distance between the two hands is getting closer.

\subsection{Dressing}

Tables 4 and 5 show that dressing requires the following: hip adductor/extensor/flexor and knee extensor strength $>$ fair, standing balance $>$ fair, hip abductor $>$ poor, shoulder abductor and elbow flexor $>$ trace, shoulder adductor $>$ fair. It can be inferred from the data in Table 5 which shows the cut-off points of dressing: shoulder adductor, hip flexor/extensor/adductor and knee extensor, 3.5; standing balance and hip abductor, 2.5; shoulder abductor and elbow flexor, 1.5; elbow extensor, 0.5 . The reason standing balance and hip joint and knee extensor strength are required may be that the patient has to stand to raise their pants to the hips. The strength of the shoulder adductor and elbow joint allows a patient with hemiplegia to easily place their paralyzed arm in the sleeves of a garment using the opposite healthy upper limb. In addition, shoulder external rotation/abduction LOM and dressing showed a higher negative correlation than other ADL, indicating the possibility that frozen shoulders, which are common in stroke patients, may affect function.

\subsection{Toileting}

The cut-off points of toileting: hip flexor and knee extensor, 3.5; standing balance and hip extensor/abductor/adductor, 2.5 (Table 5), which implies that toileting requires balancing (standing balance $>$ F) and hip joint and knee extensor strength (Table 5, Figure 1). In toileting, the process of standing and wiping seems to be challenging. When wiping, patients with hemiplegia can compensate for the function of a paralyzed upper limb by using the upper extremity on the unaffected side. Therefore, good balancing ability and hip joint and knee extensor strength are required.

\subsection{Bathing}

As shown in Table 4, strength-related factors with correlation coefficient $\geq 0.6$ in upper extremity are as follows: shoulder adductor in grooming; elbow joint strength, and shoulder extensor/abductor/adductor in dressing; shoulder/elbow/wrist joint strength, and hand flexor in bathing. These results show that, for bathing, upper limb muscle strength is required in the distal parts more than in other daily activities. This may be because it is difficult to wipe the same side of the chest or arm, or the whole of the back, using the unaffected hand. In other words, the patient should be able to wipe the whole of their back or the unaffected side of their chest or upper arm with the other, paralyzed, hand.

\subsection{Modified Balance Scale}

Although there are some tests for the evaluation of balancing abilities, such as the Berg balance scale, the timed up and go test, the one leg get stance test, and the functional reach test, it is difficult to find a certified test that can be performed in a short time for most hemiplegic patients [33]. The limitation of the four tests mentioned above is that they provide results only numerically, which causes difficulties in determining patients ${ }^{\prime}$ postures while they are standing or sitting [33]. Such numerical information alone is 
not sufficient for understanding the status of patients or for progress to the next step for future therapy. Some evaluation tools are written in a step-by-step fashion and are useful for determining the cut-off value and for allowing the researcher to predict the patient's outcome $[20,21]$. However, there were some problems in using these for this study. Both tools use ambiguous expressions, such as minimal and maximal challenge or minimal assist. In addition, one of them employed an insufficient number of subdivisions within the groups for categorizing the severely deteriorated balancing abilities of hemiplegic patients. Therefore, it was necessary to assess the patients' balance using a modified method.

Accordingly, a new scale, shown in Table 2, was developed by combining and modifying the previously mentioned scales. This evaluation tool was able to present cut-off values for balance in ADL.

\subsection{Study Limitations}

In order to eliminate the possible effects of researcher subjectivity in the recruitment of subjects, this study was conducted on all hemiplegic patients who had been admitted to the first author within a certain time period, and who consented to participation in the study. The hospital in which the research was conducted tends to treat patients who have undergone surgery after fracture or degenerative arthropathy, and patients with spinal stenosis or disc herniation, after consulting the rehabilitation department following orthopedic admission, even if they have hemiplegia. These factors might be reflected in the results of the study, as they were not explicitly excluded by the authors. Furthermore, as this study was performed in a hospital environment, it should be taken into account that the results of performing daily activities may differ depending on the patient's home structure (especially the toilet) or other environment (Korean regulations for disabled toilets are presented in the Supplementary Materials (Figure S1)). Additionally, as this hospital was not a hospital for treating cerebral palsy and severe internal diseases, none of the subjects in the study had those problems. Therefore, more caution is needed when applying the results of this study in patients with cerebral palsy and severe medical conditions. It should also be noted that not all of the significant factors tested in this study need to be above their cut-off values for the patients to perform each ADL independently. The results of this study are not absolute conclusions but display relatively good sensitivity and specificity. This study was a purely exploratory evaluation of the relationship between the parameters assessed in stroke patients and ADL. Without the presumption of the relevance of any particular variable, we proceeded with the assumption that there may or may not be a relationship between ADL and commonly obtained parameters. Additionally, if language evaluation and neglect tests were conducted, this study may have been more comprehensive.

\section{Conclusions}

Based on the assumption of a minimum period of rehabilitation (at least 1 month), the cut-off values of these significant factors for the one gait cycle test are a sitting balancing ability greater than grade 2 (fair), a standing balancing ability greater than grade 1 (poor), a hip extensor MRC muscle scale grade greater than 2, and other hip joint and knee extensor muscle MRC muscle scale grades greater than 1 (for greater specificity: hip flexor and abductor $>$ grade 2). Compared to the one gait cycle, the demand for muscle strength and balancing ability was increased in the $50 \mathrm{~m}$ walking test, and muscle strength in the upper limb was also required. For $50 \mathrm{~m}$ walking, the grade of the hip flexor/extensor/adductor and knee extensor muscle strength, as well as the standing balance ability, were better than fair in the MRC muscle scale or modified functional balance grades. In performing basic ADLs, patients with hemiplegia can compensate for the function of a paralyzed upper limb to some extent by using the upper extremity on the unaffected side. Therefore, balancing ability and a certain level of muscle strength (in the hip joint or knee extensor muscles) are more beneficial than an insufficiently restored upper limb. Overall, except for in eating and achieving one gait cycle, hip flexor (other hip joint strength > poor or fair) and knee extensor strength required an MRC muscle scale greater than fair grade, 
and standing balance was also necessary modified functional balance grade greater than fair grade. Upper limb motor recovery was required up to the distal parts in the order of bathing, dressing, and grooming.

There is no generally accepted value for the minimum walking distance for daily life. If an appropriate assumption can be developed about the minimum walking distance for daily life, the application of this research method could yield other interesting results.

In conclusion, in this study, the factors previously known to be related to ADL in brain impairment patients with hemiplegia were statistically validated. In addition, their importance and contribution were compared with each other and their necessary degree was confirmed.

Supplementary Materials: The following are available online at https://www.mdpi.com/article/ 10.3390/disabilities1030015/s1, Figure S1: Standards for disabled toilets (based on the Korean regulations for disabled toilets), Table S1: Chi-squared test results for feeding; Table S2: Independent $\mathrm{t}$ - test for feeding; Table S3: Spearman's rho test for feeding; Table S4: ROC curves results for feeding; Table S5: Chi-squared test for personal hygiene (grooming); Table S6: Independent $t$-test for grooming; Table S7: Spearman's rho test for personal hygiene (grooming); Table S8: ROC curve results for personal hygiene (grooming); Table S9: Independent $t$-test for dressing; Table S10: Chi-squared test results for dressing; Table S11: Spearman's rho test for dressing; Table S12: Roc curve results for dressing; Table S13: Chi-squared test for toileting; Table S14: Independent $t$-test for toileting; Table S15: Spearman's rho test for toileting; Table S16: ROC curve results for toileting; Table S17: Chi-squared test results for bathing; Table S18: Independent $t$-test for bathing; Table S19: Spearman's Rho test for bathing; Table S20: Roc-curve results for bathing; Table S21: Chi-squared test results for 1 gait cycle; Table S22: Independent $t$-test for 1 gait cycle; Table S23: Spearman's rho test for 1 gait cycle; Table S24: Roc-curve results for 1 gait cycle; Table S25: Independent $t$-test for $50 \mathrm{~m}$ walking; Table S26: Chi-squared test results for $50 \mathrm{~m}$ walking; Table S27: Spearman's Rho test for $50 \mathrm{~m}$ walking; Table S28: Roc-curve result for $50 \mathrm{~m}$ walking.

Author Contributions: Conceptualization, S.K. and Y.J.K.; methodology, S.K. and Y.J.K.; software, S.K.; validation, S.K., Y.J.K. and J.P.; formal analysis, S.K. and J.P. investigation, S.K.; resources, S.K.; data curation, S.K. and J.P. writing, S.K.; review and editing, Y.J.K. and S.K.; visualization, S.K. supervision, Y.J.K. project administration, S.K. All authors have read and agreed to the published version of the manuscript.

Funding: This research received no external funding.

Institutional Review Board Statement: The study was conducted according to the guidelines of the Declaration of Helsinki and approved by the Institutional Review Board (or Ethics Committee) of the Catholic University of Korea (MC17OESI0063), Registration number of Clinical Research Information Service (CRiS), Republic of Korea: KCT0004661.

Informed Consent Statement: Informed consent was obtained from all subjects involved in the study.

Conflicts of Interest: The authors declare no conflict of interest.

\section{References}

1. Anderson, C.S.; Linto, J.; Stewart-Wynne, E.G. A population-based assessment of the impact and burden of caregiving for long-term stroke survivors. Stroke 1995, 26, 843-849. [CrossRef]

2. Kalra, L.; Langhorne, P. Facilitating recovery: Evidence for organized stroke care. J. Rehabil. Med. 2007, 39, 97-102. [CrossRef]

3. Foulkes, M.A.; Wolf, P.A.; Price, T.R.; Mohr, J.P.; Hier, D.B. The Stroke Data Bank: Design, methods, and baseline characteristics. Stroke 1988, 19, 547-554. [CrossRef]

4. Feigenson, J.S.; McDowell, F.H.; Meese, P.; McCarthy, M.L.; Greenberg, S.D. Factors influencing outcome and length of stay in a stroke rehabilitation unit. Stroke 1987, 18, 830-836.

5. Brandstater, M.E.; de Bruin, H.; Gowland, C.; Clark, B.M. Hemiplegic gait: Analysis of temporal variables. Arch. Phys. Med. Rehabil. 1983, 64, 583-587.

6. Bohannon, R.W. Gait performance of hemiparetic stroke patients: Selected variables. Arch. Phys. Med. Rehabil. 1987, 68, 777-781. [PubMed]

7. Wade, D.T.; Hewer, R.L. Functional abilities after stroke: Measurement, natural history and prognosis. J. Neurol. Neurosurg. Psychiatry 1987, 50, 177-182. [CrossRef] [PubMed] 
8. Shelton, F.D.; Volpe, B.T.; Reding, M. Motor impairment as a predictor of functional recovery and guide to rehabilitation treatment after stroke. Neurorehabil. Neural Repair 2001, 15, 229-237. [CrossRef]

9. Hsu, A.L.; Tang, P.F.; Jan, M.H. Analysis of impairments influencing gait velocity and asymmetry of hemiplegic patients after mild to moderate stroke. Arch. Phys. Med. Rehabil. 2003, 84, 1185-1193. [CrossRef]

10. Kollen, B.; van de Port, I.; Lindeman, E.; Twisk, J.; Kwakkel, G. Predicting improvement in gait after stroke: A longitudinal prospective study. Stroke 2005, 36, 2676-2680. [CrossRef]

11. Schmid, A.A.; Puymbroeck, M.V.; Altenburger, P.A.; Miler, K.K.; Combs, S.A.; Page, S.J. Balance is associated with quality of life in chronic stroke. Top Stroke Rehabil. 2013, 20, 340-346. [CrossRef] [PubMed]

12. Hirano, Y.; Hayashi, T.; Nitta, O.; Takahashi, H.; Nishio, D.; Minakawa, T.; Kigawa, H. Prediction of independent walking ability for severely hemiplegic stroke patients at discharge from a rehabilitation hospital. J. Stroke Cerebrovasc Dis. 2016, 25, 1878-1881. [CrossRef] [PubMed]

13. Shimizu, S.; Takemura, N.; Taira, K.; Hamakawa, M.; Nakachi, Y.; Goya, M.; Yamazato, T.; Shimose, R.; Miura, H.; Tsunoda, S.; et al. Gait speed and balance function strongly determine the ability to walk independently without using a wheelchair in a facility setting for stroke patients. Kitasato Med. J. 2018, 48, 16-25.

14. Preston, E.; Ada, L.; Stanton, R.; Mahendran, N.; Dean, C.M. Prediction of independent walking in people who are nonambulatory early after stroke: A systematic review. Stroke 2021. [CrossRef]

15. Medical Research Council. Aids to the Investigation of Peripheral Nerve Injuries: War Memorandum No. 7. Revised, 2nd ed.; Her Majesty's Stationery Office: London, UK, 1943.

16. Bohannon, R.W.; Smith, M.B. Interrater reliability of a modified Ashworth scale of muscle spasticity. Phys. Ther. 1987, 67, 206-207. [CrossRef]

17. Shah, S.; Vanclay, F.; Cooper, B. Improving the sensitivity of the Barthel index for stroke rehabilitation. J. Clin. Epidemiol. 1989, 42, 703-709. [CrossRef]

18. Jung, H.Y.; Park, B.K.; Shin, H.S.; Kang, Y.K.; Pyun, S.B.; Paik, N.J.; Han, T.R. Development of the Korean version of modified Barthel index: Multi-center study for subjects with stroke. J. Korean Acad. Rehab. Med. 2007, 31, $283-297$.

19. Kang, Y.W.; Na, D.L.; Hahn, S.H. A validity study on the Korean mini-mental state examination (K-MMSE) in dementia patients J. Korean Neurol. Assoc. 1997, 15, 300-308.

20. O'Sullivan, S.B.; Schmitz, T.J. Physical Rehabilitation: Assessment and Treatment, 5th ed.; Davis Company: Philadelphia, PA, USA, 2007; p. 254.

21. Montometry, P.; Connolly, B. Motor Control and Physical Therapy; Waterloo Library Friends: Waterloo, ON, Canada, $1991 ;$ p. 75.

22. Kanji, J.N.; Anglin, R.E.S.; Hunt, D.L.; Panju, A. Does this patient with diabetes have large-fiber peripheral neuropathy? JAMA 2010, 303, 1526-1532. [CrossRef]

23. Ebru, Y.Y. Updates in ASIA examination: Sensory examination. Turk. J. Phys. Med. Rehab. 2015, 61, 56-59.

24. Kim, E.J.; Kim, S.S.; Kim, W.H.; Lee, W.J.; Nam, K.Y.; Park, C.W.; Choi, S.W. The selection of exercise stress test in hemiplegic patients. Ann. Rehabil. Med. J. Korean Acad. Rehab. Med. 2008, 32, 26-31.

25. Chan, Y.H. Biostatistics 104: Correlational analysis. Singapore Med. J. 2003, 44, 614-619. [PubMed]

26. Habibzadeh, F.; Habibzadeh, P.; Yadollahie, M. On determining the most appropriate test cut-off value: The case of tests with continuous results. Biochem. Med. 2016, 26, 297-307. [CrossRef] [PubMed]

27. Duncan, P.W.; Lai, S.M.; Keighley, J. Defining post-stroke recovery: Implications for design and interpretation of drug trials. Neuropharmacology 2000, 39, 835-841. [CrossRef]

28. DeLisa, J.A. Physical Medicine and Rehabilitation: Principles and Practice, 5th ed.; Lippincott Williams \& Wilkins: Philadelphia, PA, USA, 2010; p. 560.

29. Acar, M.; Karatas, G.K. The effect of arm sling on balance in patients with hemiplegia. Gait Posture 2010, 32, 641-644. [CrossRef] [PubMed]

30. Meyns, P.; Gestel, L.V.; Massaad, F.; Desloovere, K.; Molenaers, G.; Duysens, J. Arm swing during walking at different speeds in children with Cerebral Palsy and typically developing children. Res. Dev. Disabil. 2011, 32, 1957-1964. [CrossRef]

31. Han, S.H.; Kim, T.K.; Jang, S.H.; Kim, M.J.; Park, S.B.; Yoon, S.I.; Choi, B.K.; Lee, M.Y.; Lee, K.H. The effect of an arm sling on energy consumption while walking in hemiplegic patients: A randomized comparison. Clin. Rehabil. 2011, 25, 36-42. [CrossRef]

32. Jeong, Y.G.; Jeong, Y.J.; Koo, J.W. The effect of an arm sling used for shoulder support on gait efficiency in hemiplegic patients with stroke using walking aids. Eur. J. Phys. Rehabil. Med. 2017, 53, 410-415. [CrossRef]

33. Karen, W.H.; Marjorie, E.J. Measures of adult general performance tests: The berg balance scale, dynamic gait index, gait velocity, physical performance test, timed chair stand test, timed up and go, and tinetti performance-oriented mobility assessment. Arthritis Rheum. 2003, 49, 28-42. 